\title{
GABAergic Interneurons Facilitate Mossy Fiber Excitability in the Developing Hippocampus
}

\author{
Michiko Nakamura, ${ }^{1}$ Yuko Sekino, ${ }^{1,2}$ and Toshiya Manabe ${ }^{1,2}$ \\ ${ }^{1}$ Division of Neuronal Network, Department of Basic Medical Sciences, Institute of Medical Science, University of Tokyo, Tokyo 108-8639, Japan, and ${ }^{2}$ Core \\ Research for Evolutional Science and Technology, Japan Science and Technology Agency, Kawaguchi, 332-0012, Japan
}

\begin{abstract}
Profound activity-dependent synaptic facilitation at hippocampal mossy fiber synapses is a unique and functionally important property. Although presynaptic ionotropic receptors, such as kainate receptors, contribute partially to the facilitation in the hippocampus, the precise mechanisms of presynaptic regulation by endogenous neurotransmitters remain unclear. In this study, we report that axonal $\mathrm{GABA}_{\mathrm{A}}$ receptors on mossy fibers are involved in the activity-dependent facilitation during development. In immature mouse hippocampal slices, short-train stimulation (five pulses at $25 \mathrm{~Hz}$ ) caused frequency-dependent facilitation of not only postsynaptic responses but also presynaptic fiber volleys that represent presynaptic activities. This fiber volley facilitation was inhibited by selective $\mathrm{GABA}_{\mathrm{A}}$ receptor antagonists, or by enkephalin that selectively suppresses excitability of interneurons. Furthermore, we directly demonstrated that this facilitation resulted from depolarization of mossy fibers in imaging experiments using a voltage-sensitive dye. This increased mossy fiber excitability caused by depolarizing action of GABA gradually decreased with development and eventually disappeared at around post-

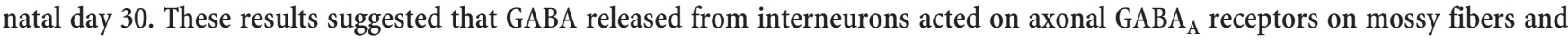
contributed at least partially to the activity- and age-dependent facilitation in the hippocampus.
\end{abstract}

Key words: $\mathrm{GABA}_{\mathrm{A}}$ receptor; hippocampus; synaptic transmission; development; mossy fiber; presynaptic facilitation

\section{Introduction}

The hippocampus is a critical brain structure associated with certain types of memory (Milner et al., 1998), and hippocampal synaptic plasticity has been regarded as a cellular model of memory formation (Lynch, 2004). The mossy fiber synapse in the hippocampus has a variety of unique morphological and physiological properties (Henze et al., 2000), among which profound activity-dependent synaptic facilitation, such as paired-pulse facilitation and frequency facilitation caused by repetitive lowfrequency stimulation, is one of the most distinctive features observed at mossy fiber synapses (Nicoll and Schmitz, 2005). Although this kind of short-term activity-dependent facilitation is generally caused by cumulative elevations of $\mathrm{Ca}^{2+}$ concentrations in the presynaptic terminal (Zucker and Regehr, 2002), other mechanisms for the profound short-term synaptic facilitation have been reported at the mossy fiber synapse: for instance, activation of presynaptic kainate receptors, a kind of ionotropic

Received Aug. 10, 2006; revised Dec. 25, 2006; accepted Dec. 29, 2006.

This work was supported by Grants-in-Aid for Scientific Research, the Center for Brain Medical Science, 21st Century Center of Excellence Program from the Ministry of Education, Science, Sports, Culture and Technology of Japan, and by Research Institute of Science and Technology for Society, Japan Science and Technology Agency (all to T.M.). M.N. was a recipient of Research Fellowship of the Japan Society for the Promotion of Science for Young Scientists. We are grateful to Dr. Haruyuki Kamiya (Hokkaido University, Sapporo, Japan) for valuable comments on this manuscript and expert advice about imaging techniques and to Drs. Shizuka Kobayashi (University of Tokyo, Tokyo, Japan) and Ayako M. Watabe (University of Tokyo) for helpful comments on this manuscript.

Correspondence should be addressed to Toshiya Manabe, Division of Neuronal Network, Department of Basic Medical Sciences, Institute of Medical Science, University of Tokyo, Tokyo 108-8639, Japan. E-mail: tmanabe-tky@umin.ac.jp.

DOl:10.1523/JNEUROSCI.4672-06.2007

Copyright $\odot 2007$ Society for Neuroscience $\quad$ 0270-6474/07/271365-09\$15.00/0 glutamate receptors, depolarizes mossy fibers, resulting in the facilitation of a $\mathrm{Ca}^{2+}$ influx into presynaptic terminals in response to the second stimulus of paired pulses (Kamiya et al., 2002).

Another characteristic feature of the mossy fiber synapse is the presence of ionotropic $\mathrm{GABA}_{\mathrm{A}}$ receptors on axonal membranes and synaptic terminals (Ruiz et al., 2003). Previously, it has been suggested that activation of presynaptic $\mathrm{GABA}_{\mathrm{A}}$ receptors may also depolarize mossy fiber axons and/or terminals, which might regulate glutamate release from the mossy fiber terminal (Ruiz et al., 2003; Jang et al., 2006). It has also been reported that synaptically released $\mathrm{GABA}$ may activate $\mathrm{GABA}_{\mathrm{A}}$ receptors on mossy fibers (Jang et al., 2006), and GABA released from the mossy fiber terminal (Walker et al., 2001; Gutiérrez, 2003) is a candidate that activates presynaptic $\mathrm{GABA}_{\mathrm{A}}$ receptors, although it has not yet been determined how the presynaptic $\mathrm{GABA}_{\mathrm{A}}$ receptor is activated. Thus, although the mossy fiber synapse plays a principal role as an excitatory synapse, it exceptionally shows a characteristic as an inhibitory synapse as well and its function may be regulated presynaptically by $\mathrm{GABA}_{\mathrm{A}}$ receptors, but the exact role of $\mathrm{GABA}_{\mathrm{A}}$ receptors on the mossy fiber is still unknown.

In the present study, we examined the roles of axonal $\mathrm{GABA}_{\mathrm{A}}$ receptors at mossy fiber synapses with electrophysiological and optical imaging techniques. We found that, at the immature mossy fiber synapse, GABA released from inhibitory interneurons depolarizes mossy fibers via activation of axonal $\mathrm{GABA}_{\mathrm{A}}$ receptors, resulting in increased mossy fiber excitability and the increased number of activated axons, whereas this depolarizing action of GABA gradually decreases with development and eventually disappears at around postnatal day 30 (P30). This novel 
type of the regulation of axonal excitability at least partially contributes to the profound activity-dependent synaptic facilitation at mossy fiber synapses, and possibly to their functional development.

\section{Materials and Methods}

Animals. All experiments were performed according to the guidelines of the Animal Care and Experimentation Committee of the University of Tokyo (Tokyo, Japan). In this paper, mice from P9 to P11 were designated as immature.

Slice preparations and field potential recordings. C57BL/6J mice (P9P70; male) were anesthetized deeply with halothane and decapitated. The brain was quickly removed and immersed in an ice-cold Ringer solution composed of the following (in mM): $119 \mathrm{NaCl}, 2.5 \mathrm{KCl}, 1.3 \mathrm{MgSO}_{4}, 2.5$ $\mathrm{CaCl}_{2}, 1.0 \mathrm{NaH}_{2} \mathrm{PO}_{4}, 26.2 \mathrm{NaHCO}_{3}$, and 11 glucose. The solution had been saturated with $95 \% \mathrm{O}_{2}$ and $5 \% \mathrm{CO}_{2}$. Hippocampi were dissected out and transverse slices ( $400 \mu \mathrm{m}$ thick) were prepared with a microslicer (Vibratome; Vibratome, St. Louis, MO). Slices were placed in a humidified holding chamber for at least $1 \mathrm{~h}$ and then transferred to a recording chamber that was continuously superfused at a rate of $\sim 2 \mathrm{ml} / \mathrm{min}$ with the Ringer solution. To exclude the influence of the cell body of granule cells in the dentate gyrus (DG), we isolated mossy fibers from the cell body using a fine razor blade under a stereomicroscope (see Figs. $1 A, 7 B$ ). Electrical stimuli were delivered through a bipolar tungsten stimulating electrode inserted into the hilus. The stimulus strength was adjusted between 1.5 and $3.0 \mathrm{~V}$ to evoke the first EPSPs of $\sim 0.1 \mathrm{mV}$. Field EPSPs and fiber volleys were recorded in the stratum lucidum of the CA3 region with a glass microelectrode filled with $2 \mathrm{M} \mathrm{NaCl}$. Local application of the drug was made from the tip of U-shaped tubing. All recordings were performed at $24-26^{\circ} \mathrm{C}$.

Data acquisition. Extracellular field potentials were recorded using an Axopatch-1D amplifier (Molecular Devices, Union City, CA). The signal was filtered at $1 \mathrm{kHz}$, digitized at $10 \mathrm{kHz}$, and stored on a personal computer equipped with pCLAMP 9.2 (Molecular Devices). The EPSP amplitude was measured as a peak value. The fiber volley amplitude was measured as a difference between the initial positive and the following negative peak.

Statistical analysis. All values are expressed as the mean \pm SEM. Statistical analysis was performed using Student's $t$ test (paired) to determine whether there was a statistically significant difference between the means $\left({ }^{*} p<0.05\right)$.

Optical imaging of the presynaptic voltage transient in mossy fibers. For the optical imaging of voltage transients in the presynaptic membrane, a fluorescent voltage-sensitive dye, di-8-ANEPPS (Invitrogen, Eugene, OR), was used (Kamiya et al., 2002). The labeling solution containing 1 mM di-8-ANEPPS dissolved in 2\% Pluronic F-127/DMSO was locally pressure-injected into the stratum lucidum. Slices were placed in a holding chamber for $\sim 10 \mathrm{~h}$ at room temperature until the dye diffused along mossy fiber axons. After the staining was achieved, slices were transferred into a recording chamber mounted on an upright fluorescence microscope stage (BX50WI; Olympus, Tokyo, Japan). Images of hippocampal slices (see Fig. $7 B, C$ ) were obtained using a DP70 CCD camera (Olympus). Optical images of the voltage transient were obtained using the fast image acquisition system with a high-speed complementary metal-oxide semiconductor image sensor $(100 \times 100$ pixel; $10 \mathrm{~mm} \times 10 \mathrm{~mm})$ (MiCAM ULTIMA-L; Brainvision, Tokyo, Japan) mounted on the upright fluorescence microscope stage having a $480-550 \mathrm{~nm}$ excitation filter, a $590 \mathrm{~nm}$ absorption filter (U0MSWG2 mirror unit; Olympus), and a halogen lamp (150 W) as a light source. Magnification was adjusted by a $60 \times$ objective lens (LUMPlanFI/IR $60 \times / 0.90$ numerical aperture; Olympus) and a $0.25 \times$ collector lens (U-TV $0.25 \times \mathrm{XC}$; Olympus). The final imaging area of the preparation was $0.66 \times 0.66 \mathrm{~mm}$. Images were acquired at a $10 \mathrm{kHz}$ frame rate in the differential mode. The ratio of the fractional changes in fluorescence $(\Delta \mathrm{F} / \mathrm{F})$ was calculated and used as the optical signals. A short-train stimulus of five pulses at $25 \mathrm{~Hz}$ was delivered every $30 \mathrm{~s}$ through a stimulating electrode inserted in the hilus, and neuronal activities in the CA3 region were detected as a change in fluorescence of the voltage-sensitive dye. Signals were averaged for 12 trials.
The differential image, processed with a software spatial filter for $2 \times 2$ pixels, was represented by a pseudocolor display in which red corresponded to the largest fluorescence decrease and membrane depolarization, yellow to the medium decrease, and green to the smallest.

Drugs. Drugs used in this study were $\left(2 S, 2^{\prime} R, 3^{\prime} \mathrm{R}\right)-2-\left(2^{\prime}, 3^{\prime}-\right.$ dicarboxycyclopropyl)glycine (DCG-IV), 6-cyano-7-nitroquinoxaline2,3-dione (CNQX) (Tocris Bioscience, Avonmouth, UK), muscimol, SR95531, bicuculline, picrotoxin, enkephalin (methionine enkephalin) (Sigma, St. Louis, MO), tetrodotoxin (TTX) (Sankyo, Tokyo, Japan), and di-8-ANEPPS (Invitrogen).

\section{Results}

\section{Activity-dependent facilitation of EPSPs and fiber volleys at the developing mossy fiber synapse}

In all experiments, we used hippocampal slices in which the cut had been made between the mossy fiber and the cell body of granule cells in the DG to prevent possible influence of granule cells on mossy fiber excitability (Figs. $1 A, 7 B$ ). To record EPSPs and fiber volleys in the stratum lucidum of the CA3 region, a short-train stimulus of five pulses at $25 \mathrm{~Hz}$ was delivered at $30 \mathrm{~s}$ intervals through a stimulating electrode inserted in the hilus (Fig. $1 B$ ). The recorded EPSPs exhibited drastic facilitation during the train at P30 when the morphological properties of mossy fibers are already mature (Amaral and Dent, 1981) (Fig. 1C), and a similar degree of the facilitation could be induced repeatedly at $30 \mathrm{~s}$ intervals as shown in the following figures. This marked facilitation is one of the characteristics of the mossy fiber synapse, and indeed, the recorded EPSP was almost completely inhibited by $1 \mu \mathrm{M}$ DCG-IV, a selective group II metabotropic glutamate receptor (mGluR) agonist that selectively inhibits mossy fiber responses (data not shown) (Kamiya et al., 1996; Yokoi et al., 1996). EPSPs were successively increased during the train, and the amplitude of the fifth EPSP was increased to $1106 \pm 67 \%$ $(n=10 ; p<0.0001)$ of that of the first EPSP (Fig. 1C,D). In contrast, the amplitude of the second fiber volley was indistinguishable from that of the first fiber volley, and the amplitude of the fifth fiber volley was only slightly increased $(116 \pm 2 \%$ of the first fiber volley; $n=10 ; p=0.00760$ ), although the facilitation was much less than that of EPSPs (Fig. 1C,E). For eliciting a similar degree of the enhancement of EPSPs evoked by single pulses, the stimulus strength was required to be increased extremely to recruit much more stimulated axons, and the fiber volleys became much larger in amplitude (Fig. $1 \mathrm{~F}$ ). These results indicated that the facilitation of EPSPs during the train stimulation at P30 was caused primarily by an increase in synaptic efficacy, but not by the recruitment of axons that had not been activated by the first pulse.

On the contrary, at the immature mossy fiber synapse, the response of fiber volleys to the train stimulation exhibited drastic facilitation (Fig. 2A). At P10, EPSPs showed a similar degree of facilitation during the train $(934 \pm 60 \%$ of the first EPSP amplitude; $n=13 ; p<0.0001$ ) (Fig. $2 A, B$ ) to that at P30, and the fiber volley also exhibited a clear increase in amplitude: even the fiber volley evoked by the second pulse was significantly increased in amplitude ( $124 \pm 4 \% ; n=13 ; p<0.0001$ ) (Fig. $2 A, C$ ), and the fiber volley evoked by the fifth pulse was increased to $166 \pm 4 \%$ $(n=13 ; p<0.0001)$ of that of the first fiber volley. This facilitation of fiber volleys contributed partially to that of EPSPs (Fig. $2 B, D$, closed circles), although the facilitation of EPSPs was due primarily to an increase in synaptic efficacy (Fig. $2 D$ ). The same degree of facilitation in fiber volley amplitudes was also observed in intact slices without the cut $(161 \pm 3 \% ; n=10 ; p=0.536)$, indicating that the damage caused by the cut made between the 
A

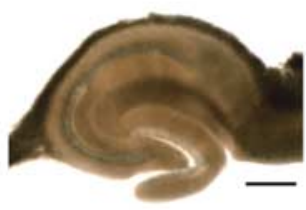

B

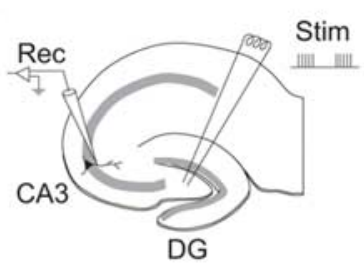

C

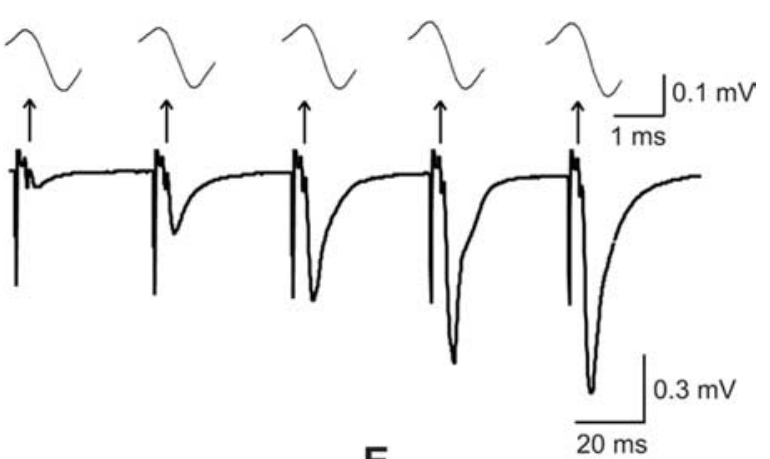

D

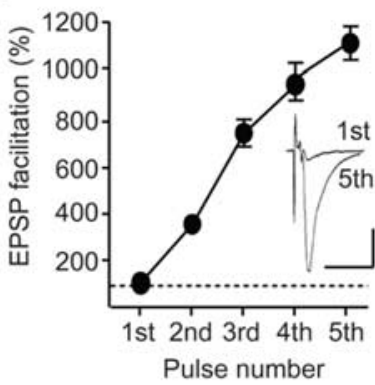

E

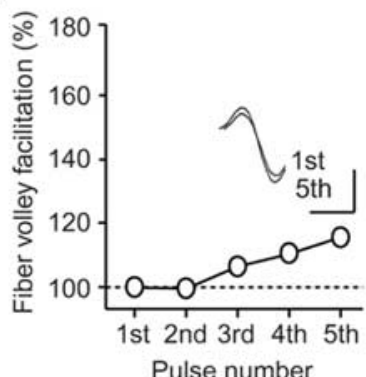

$\mathbf{F}$

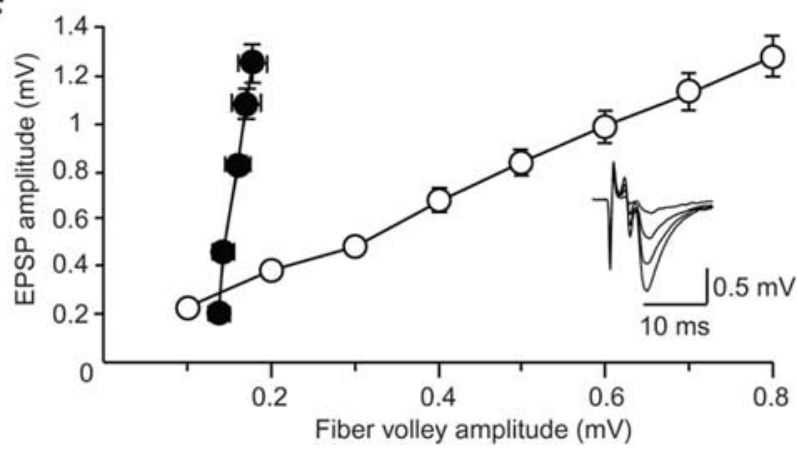

Figure 1. Frequency facilitation at hippocampal mossy fiber synapses at P30. A, A light micrograph of the hippocampal slice in which the cut was made between the granule cell layer and the hilus. Scale bar, $500 \mu \mathrm{m}$. B, A schematic illustration of the hippocampal slice showing the electrode arrangement. A stimulating electrode (Stim) was placed in the hilus, and EPSPS were recorded with a recording glass electrode $(\operatorname{Rec})$ in the stratum lucidum of the $C A 3$ region. C, Representative traces recorded at P30 evoked by a short-train stimulus of five pulses at $25 \mathrm{~Hz}$. Top traces are the expanded fiber volleys elicited by each pulse. D, Facilitation of the EPSP (fifth/first) during the train $(n=10)$. In the inset, the traces of the first and fifth EPSPs are superimposed. Calibration: $20 \mathrm{~ms}, 0.3 \mathrm{mV}$. E, Facilitation of the fiber volley (fifth/first) during the train $(n=10)$. In the inset, the traces of the first and fifth fiber volleys are superimposed. Calibration: $1 \mathrm{~ms}, 0.1 \mathrm{mV}$. F, The input- output relationship obtained by changing the stimulus strength (open circles) and the fiber volley-EPSP relationship during the train stimulation (closed circles) at P30 $(n=10)$. In the inset, the traces evoked with various stimulus strengths are superimposed.

granule cell layer and hilus was not associated with the fiber volley facilitation.

The results so far suggest that there may be developmental alteration in the regulation of activity-dependent facilitation of
A

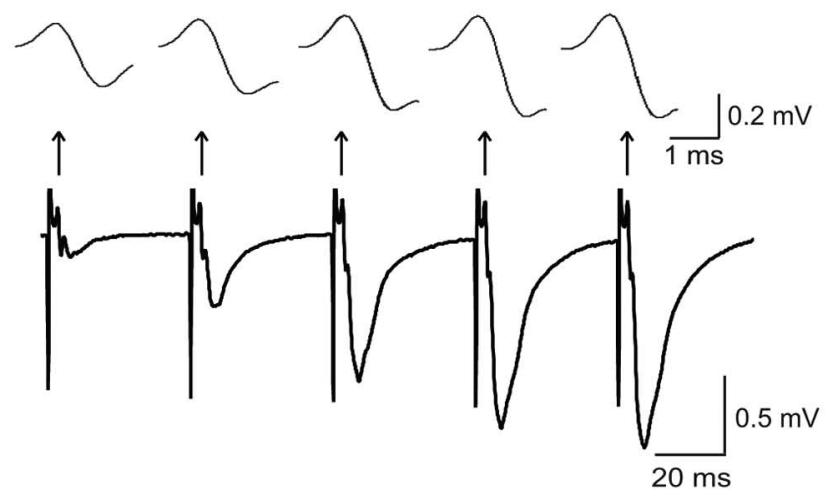

B

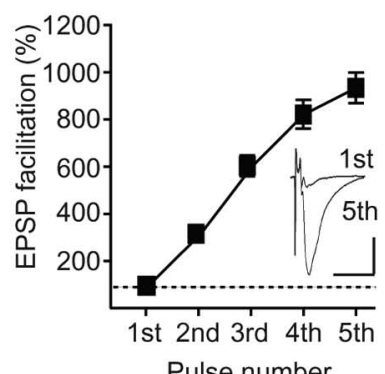

C

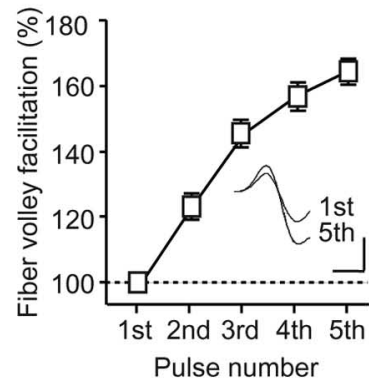

D

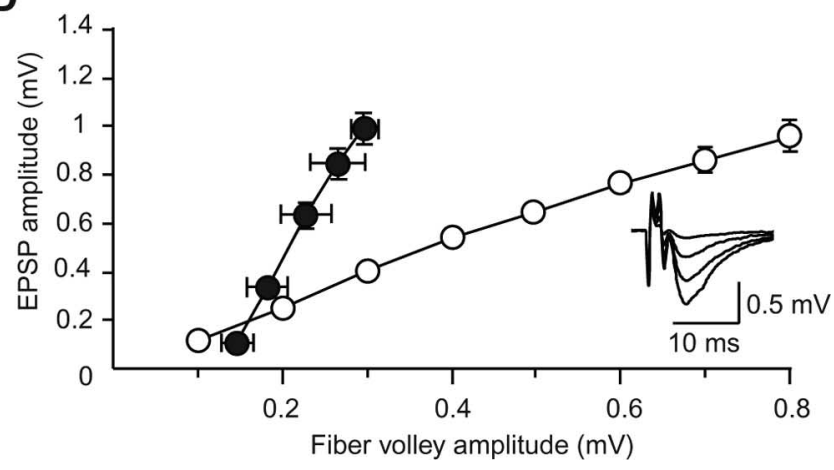

Figure 2. Frequency facilitation at hippocampal mossy fiber synapses at P10. A, Representative traces recorded at $\mathrm{P} 10$ evoked by a short-train stimulus of five pulses at $25 \mathrm{~Hz}$. Top traces are the expanded fiber volleys elicited by each pulse. $\boldsymbol{B}$, Facilitation of the EPSP (fifth/first) during the train $(n=13)$. In the inset, the traces of the first and fifth EPSPs are superimposed. Calibration: $20 \mathrm{~ms}, 0.3 \mathrm{mV}$. C, Facilitation of the fiber volley (fifth/first) during the train ( $n=$ 13). In the inset, the traces of the first and fifth fiber volleys are superimposed. Calibration: $1 \mathrm{~ms}$, $0.1 \mathrm{mV}$. D, The input-output relationship obtained by changing the stimulus strength (open circles) and the fiber volley-EPSP relationship during the train stimulation (closed circles) at P10 ( $n=13)$. In the inset, the traces evoked with various stimulus strengths are superimposed.

fiber volleys. In fact, the facilitation ratio of fiber volleys was gradually decreased with postnatal development (Fig. 3), suggesting that the fiber volley facilitation elicited by the train was unique to immature mossy fiber synapses and may have a critical role in activity-dependent short-term synaptic plasticity at early stages during development.

Presynaptic $\mathrm{GABA}_{\mathrm{A}}$ receptors are responsible for the fiber volley facilitation at immature mossy fiber synapses

The present results showing that the amplitude of fiber volleys was activity-dependently increased at early developmental stages suggest that endogenous neurotransmitters released during the train stimulation, such as glutamate or GABA, may modulate the 


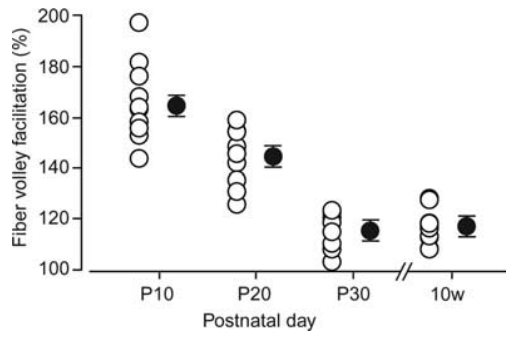

Figure 3. Developmental changes in the fiber volley facilitation. The facilitation ratio (fifth/ first) at various postnatal days is plotted (P10, $n=13 ; \mathrm{P} 20, n=9 ; \mathrm{P} 30, n=10 ; 10 \mathrm{w}, n=10)$. Open and closed circles represent individual results and the means, respectively.

excitability of mossy fibers. This was actually the case, because the fiber volley facilitation was almost completely blocked when 100 $\mu \mathrm{M} \mathrm{Cd}{ }^{2+}$, a general voltage-dependent $\mathrm{Ca}^{2+}$ channel blocker, was perfused to the slices at P10 to block synaptic transmission (control, $173 \pm 8 \%$; $\mathrm{Cd}^{2+}, 114 \pm 2 \% ; n=7 ; p=0.000243$ ) (Fig. $4 A)$.

It has been demonstrated that activation of presynaptic kainate receptors on mossy fibers depolarizes the axonal membrane and enhances the fiber volley amplitude (Kamiya and Ozawa, 2000; Schmitz et al., 2001) and, thus, the neurotransmitter glutamate is one of the candidates for a mediator of the fiber volley facilitation. Because synaptic transmission and plasticity at the mossy fiber synapse are regulated by the presynaptic group II mGluR (Kamiya et al., 1996; Kobayashi et al., 1996; Yokoi et al., 1996), we have examined whether the group II mGluR agonist DCG-IV affects the fiber volley facilitation, but found no effect of DCG-IV on the facilitation (control, $160 \pm 3 \%$; DCG-IV, $164 \pm$ $4 \% ; n=11 ; p=0.250$ ) (Fig. $4 B$ ).

We next examined possible involvement of GABA, another candidate for a mediator of the fiber volley facilitation, because activation of presynaptic $\mathrm{GABA}_{\mathrm{A}}$ receptors has been suggested previously to depolarize mossy fiber axons and/or terminals (Ruiz et al., 2003; Jang et al., 2006) and synaptically released GABA may act on mossy fiber terminals (Vogt and Nicoll, 1999). To examine the action of GABA in the absence of excitatory synaptic transmission, slices were first treated with the nonNMDA receptor antagonist CNQX $(10 \mu \mathrm{M})$. CNQX had no effect on the first fiber volley (Fig. 4C), although the fifth fiber volley during the train was slightly decreased (control, $167 \pm 8 \%$; CNQX. $144 \pm 4 \% ; n=6 ; p=0.00974$ ) (Fig. $4 D, E$ ), presumably because of the inhibition of presynaptic kainate receptors on mossy fibers (Kamiya et al., 2002). When the $\mathrm{GABA}_{\mathrm{A}}$ receptor antagonist SR95531 was perfused in the presence of CNQX, the fiber volley facilitation was greatly decreased (CNQX, $143 \pm 5 \%$; CNQX plus SR95531, $107 \pm 1 \% ; n=6 ; p=0.000290$ ) (Fig. $4 D, E)$, although the first fiber volley was not affected by the antagonist (Fig. 4C). Because mossy fibers were isolated from the cell body of granule cells, the decrease in the fifth fiber volley by SR95531 was not attributable to the effect of the antagonist on the granule cell. In addition, the facilitation was also suppressed in the presence of another $\mathrm{GABA}_{\mathrm{A}}$ receptor blocker, either $30 \mu \mathrm{M}$ bicuculline or $100 \mu \mathrm{M}$ picrotoxin $(109 \pm 2 \%, n=7, p<0.0001$; $110 \pm 5 \%, n=9, p<0.0001$, respectively). Figure $4 F$ shows a developmental profile of the $\mathrm{GABA}_{\mathrm{A}}$ receptor-dependent component of the fiber volley facilitation: the percent inhibition by SR95531 was decreased with development [P10, $36 \pm 4 \%, n=6$; P20, $24 \pm 6 \%, n=6$; P30, $9 \pm 1 \%, n=5 ; 10$ weeks after birth $(10 \mathrm{w}), 6 \pm 2 \%, n=5]$. These results suggested that the activitydependent activation of presynaptic $\mathrm{GABA}_{\mathrm{A}}$ receptors by synap- tically released GABA was responsible for the facilitation of fiber volleys during the train stimulation.

\section{Activation of axonal $\mathrm{GABA}_{\mathrm{A}}$ receptors depolarizes mossy fibers and increases axonal excitability}

We examined directly whether GABA can increase the excitability of mossy fibers by applying muscimol, a $\mathrm{GABA}_{\mathrm{A}}$ receptor agonist, to immature hippocampal slices (Fig. 5). Muscimol (0.1 $\mu \mathrm{M})$ reversibly increased the amplitude of fiber volleys (131 \pm $3 \% ; n=12 ; p=0.000110)$ (Fig. $5 A)$ and EPSPs $(129 \pm 4 \% ; n=$ $12 ; p=0.00313$ ) (Fig. $5 B$ ), indicating that activation of $\mathrm{GABA}_{\mathrm{A}}$ receptors increased the excitability of mossy fibers, presumably via presynaptic $\mathrm{GABA}_{\mathrm{A}}$ receptors. The effect of muscimol on fiber volleys (open columns, P10, $131 \pm 3 \%, n=12$; P20, $118 \pm 6 \%$, $n=6$; P30, $116 \pm 5 \%, n=6$ ) and EPSPs (closed columns, P10, $129 \pm 4 \%, n=12 ; \mathrm{P} 20,120 \pm 4 \%, n=6 ; \mathrm{P} 30,117 \pm 5 \%, n=6)$ was also changed in an age-dependent manner (Fig. $5 C$ ).

To identify the site on which GABA acts for inducing the fiber volley facilitation, we next performed experiments using local perfusion of the $\mathrm{GABA}_{\mathrm{A}}$ receptor antagonist SR95531. When SR95531 was locally perfused close to the stimulation site (hilus) in the presence of CNQX, the fiber volley facilitation was greatly reduced [CNQX, $149 \pm 4 \%$; CNQX plus SR95531, $117 \pm 3 \%$; CNQX wash, $143 \pm 5 \% ; n=7 ; p=0.000178$ (CNQX vs CNQX plus SR95531)], whereas local perfusion of the antagonist near the recording site in the stratum lucidum (CA3) had little effect on the facilitation [CNQX, $150 \pm 3 \%$; CNQX plus SR95531, $149 \pm 5 \%$; CNQX wash, $150 \pm 4 \% ; n=7 ; p=0.738$ (CNQX vs CNQX plus SR95531)] (Fig. 6A, $B$ ). These results indicated that axonal $\mathrm{GABA}_{\mathrm{A}}$ receptors on mossy fibers near the stimulation site in the hilus were responsible for the induction of the fiber volley facilitation.

We also examined whether $\mathrm{GABA}_{\mathrm{A}}$ receptors at or near the synaptic terminal are involved in the regulation of axonal excitability by applying muscimol locally in the stratum lucidum. We found that muscimol locally applied in the stratum lucidum failed to show any effect on EPSPs $(99 \pm 1 \% ; n=8 ; p=0.714$ ) (Fig. $6 C, D)$ as well as fiber volleys $(100 \pm 1 \% ; n=8 ; p=0.778)$ (Fig. $6 E, F$ ), whereas muscimol locally applied in the hilus significantly increased EPSP (130 $\pm 5 \% ; n=7 ; p=0.000727)$ (Fig. $6 C, D)$ as well as fiber volley $(128 \pm 6 \% ; n=7 ; p=0.00393$ ) (Fig. $6 E, F)$ amplitudes, which was consistent with the result shown above (Fig. 6A,B). These results strongly suggested that functional $\mathrm{GABA}_{\mathrm{A}}$ receptors were present in the axon, but not in the synaptic terminal of mossy fibers.

To confirm more directly that the increase in fiber volley amplitudes was mediated by depolarization induced by the axonal $\mathrm{GABA}_{\mathrm{A}}$ receptor activation, we measured the membrane potential of mossy fibers with the imaging technique (Fig. 7). Mossy fibers were stained with the fluorescent voltage-sensitive dye di8-ANEPPS locally injected into the mossy fiber axon bundle (Fig. $7 A-C)$. When the same train stimulation used in electrophysiological experiments to induce the frequency facilitation was delivered in the presence of $10 \mu \mathrm{M}$ CNQX, transient depolarization in response to each pulse (Fig. $7 D$ ), as well as gradual depolarization of the baseline $(\Delta \mathrm{F} / \mathrm{F}, 0.049 \pm 0.004 \% ; n=12)($ Fig. $7 D, F)$, was observed. In the presence of $1 \mu \mathrm{M}$ TTX, a sodium channel blocker, both transient and gradual depolarization completely disappeared (Fig. 7 E,F), indicating that both types of depolarization were induced by neuronal activities. It should be noted that the voltage transients were also increased during the train stimulation (the fifth transient, $157.5 \pm 9.7 \% ; n=12 ; p=0.000104$ ) 
A
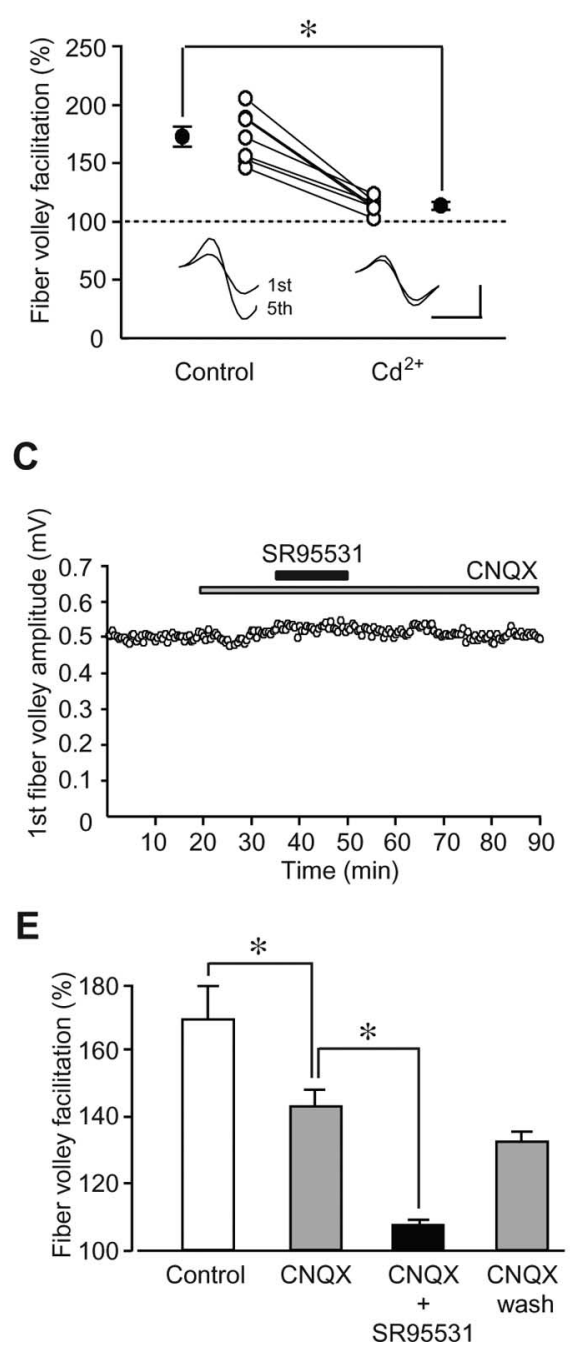

B

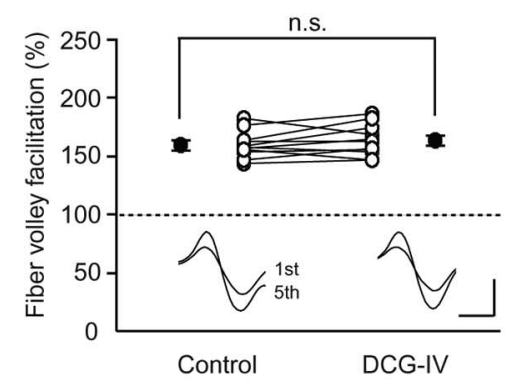

D

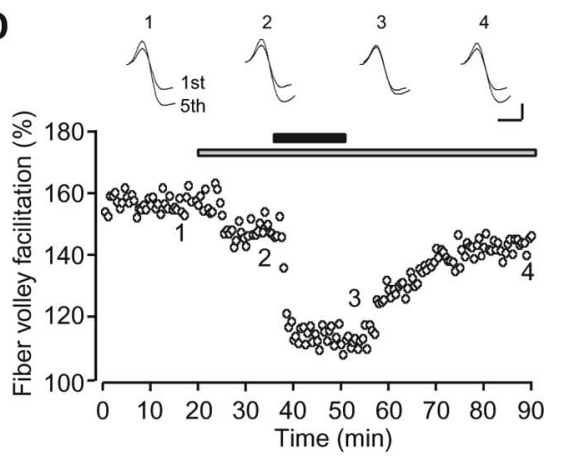

$\mathbf{F}$

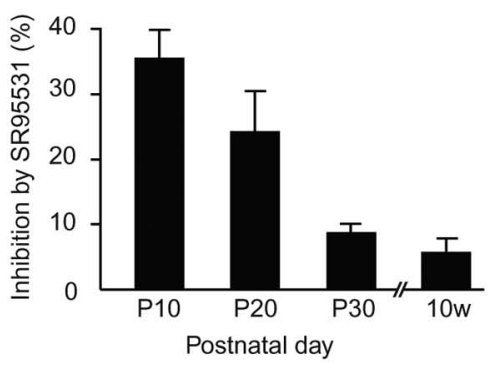

Figure 4. Axonal $\mathrm{GABA}_{\mathrm{A}}$ receptors modulate the fiber volley facilitation at immature mossy fiber synapses. $\boldsymbol{A}$, Effects of $\mathrm{Cd}^{2+}$ $(100 \mu \mathrm{m})$ on the fiber volley facilitation. Open circles represent individual results, and the data points from the same slice are connected by the line. Closed circles indicate the means $(n=7 ; p=0.000243)$. In the inset, the traces of the first and fifth fiber volleys are superimposed in the absence (Control) and presence $\left(\mathrm{Cd}^{2+}\right)$ of $\mathrm{Cd}^{2+}$. B, Effects of DCG-IV (1 $\left.\mu \mathrm{m}\right)$ on the fiber volley facilitation. Open circles represent individual results, and the data points from the same slice are connected by the line. Closed circles indicate the means $(n=7 ; p=0.250$ ). In the inset, the traces of the first and fifth fiber volleys are superimposed in the absence (Control) and presence (DCG-IV) of DCG-IV. n.S., Not significant. C, The time course of the first fiber volley amplitude before, during, and after the application of CNQX (10 $\mu \mathrm{M})$ and SR95531 (10 $\mu \mathrm{M})$, which is indicated by the horizontal bars. D, The time course of the fiber volley facilitation (fifth/first) before, during, and after the application of CNQX and SR95531. In the inset, representative traces recorded at the times indicated by the numbers in the graph are shown. $\boldsymbol{E}$, The fiber volley facilitation $(n=$ 6) under normal conditions (open column), in the presence of CNQX (left gray column) and CNQX + SR95531 (closed column), and after the washout of SR95531 (right gray column). $F$, Developmental changes of the inhibition of the fiber volley facilitation by SR95531. Calibrations: $\boldsymbol{A}, 1 \mathrm{~ms}, 0.2 \mathrm{mV} ; \boldsymbol{B}, 1 \mathrm{~ms}, 0.2 \mathrm{mV} ; \boldsymbol{D}, 1 \mathrm{~ms}, 0.2 \mathrm{mV}$. ${ }^{*} p<0.05$ (paired $t$ test).

(Fig. $7 D, G$ ), which was consistent with the electrophysiological results (Fig. 2C).

\section{GABAergic interneurons contribute to the fiber volley facilitation}

Previous studies have shown that the granule cells in the DG express GABAergic phenotypes (Gutiérrez, 2003), and glutamate and GABA are coreleased from the mossy fiber terminal during the first 3 weeks after birth (Walker et al., 2001; Safiulina et al., 2006). Thus, the source of GABA responsible for the fiber volley facilitation may be not only GABAergic interneurons but also the mossy fiber terminal itself.
To differentiate these two possibilities, we firstly examined the effect of enkephalin, a $\mu$-and $\delta$-opioid receptor agonist, on the fiber volley facilitation, because the opioid receptors are selectively expressed on inhibitory interneurons, but not on pyramidal cells, in the hippocampus (Stumm et al., 2004) and enkephalin selectively decreases the excitability of GABAergic interneurons (Madison and Nicoll, 1988; Manzoni et al., 1994). Although $1 \mu \mathrm{M}$ enkephalin had no effect on the first fiber volley ( $98 \pm 4 \%$ of control; $n=12 ; p=0.248$ ) (Fig. $8 A$ ), it partially and reversibly inhibited the fiber volley facilitation (CNQX, $162 \pm 2 \%$ of control; CNQX plus enkephalin, $132 \pm 4 \%$ of control; $n=12 ; p=0.000447$ ) (Fig. $8 B, C$ ), indicating that the basal excitability of mossy fibers was not affected by ambient GABA, but that the facilitation was at least partially mediated by GABA released synaptically from interneurons.

\section{Discussion}

Axonal $\mathrm{GABA}_{\mathrm{A}}$ receptors in activitydependent fiber volley facilitation

Short-term synaptic facilitation at mossy fiber synapses allows a rapid increase of the synaptic gain in an activity-dependent manner: for example, a single spike in a DG granule cell is unlikely to evoke action potentials in CA3 pyramidal neurons, but a train of spikes often elicits action potentials with a high probability (Henze et al., 2002). Therefore, the activity-dependent facilitation at mossy fiber synapses might be essential for information transfer from the DG to the CA3 region. In the mossy fiber synapses, activity-dependent synaptic facilitation is known to be caused by (1) an increased level of residual $\mathrm{Ca}^{2+}$ in the presynaptic terminal (residual $\mathrm{Ca}^{2+}$ hypothesis) (Katz and Miledi, 1968), (2) an increased $\mathrm{Ca}^{2+}$ influx to the presynaptic terminal by broadening of action potentials (Geiger and Jonas, 2000), and (3) saturation of endogenous $\mathrm{Ca}^{2+}$ buffers, such as calbindin-D28k (Blatow et al., 2003). In addition to these direct contributions of the intraterminal $\mathrm{Ca}^{2+}$, presynaptic ionotropic receptors are also associated with the activity-dependent synaptic facilitation via the regulation of presynaptic $\mathrm{Ca}^{2+}$ concentrations (Nicoll and Schmitz, 2005); for example, presynaptic kainate receptors at mossy fiber synapses are also involved in the frequency facilitation of mossy fiber synaptic transmission (Schmitz et al., 2001; Kamiya et al., 2002). Furthermore, previous studies have implied that $\mathrm{GABA}_{\mathrm{A}}$ receptor-mediated fiber volley facilitation might result from presynaptic depolarization of mossy fibers (Ruiz et al., 2003; Jang et al., 2006). In the present study, synaptically released GABA acts only on axonal $\mathrm{GABA}_{\mathrm{A}}$ receptors, and there seem to be no functional $\mathrm{GABA}_{\mathrm{A}}$ receptors at synaptic terminals (Fig. 6), suggesting 
A

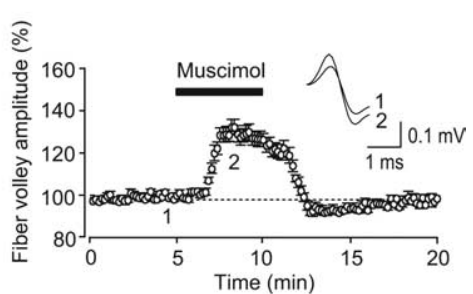

B

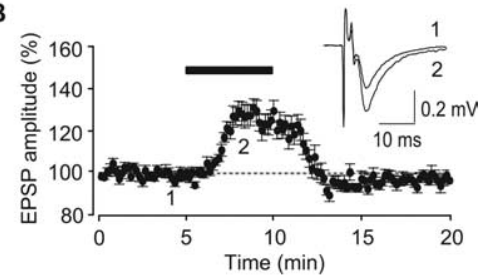

C

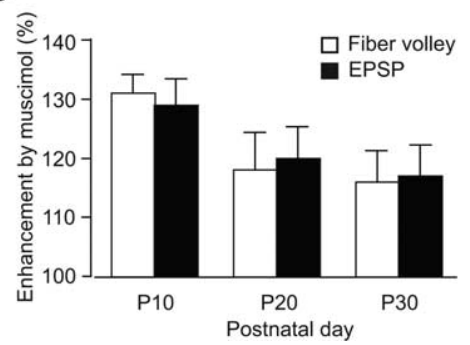

Figure 5. Muscimol-induced enhancement of fiber volleys and EPSPs at immature mossy fiber synapses. $\boldsymbol{A}, \boldsymbol{B}$, The time course of the amplitudes of fiber volleys $(\boldsymbol{A})$ and EPSPs $(\boldsymbol{B})$ before, during, and after the application of $0.1 \mu \mathrm{m}$ muscimol at P10. In the inset, representative traces recorded at the times indicated by the numbers in the graph are shown. $\mathbf{C}$, Developmenta changes of the enhancement of fiber volley amplitudes (open columns) and EPSPs (closed columns).

that the number of activated axons is increased by the activation of axonal $\mathrm{GABA}_{\mathrm{A}}$ receptors on immature mossy fibers. Thus, in addition to the mechanisms for presynaptic modulation described above, the novel presynaptic mechanism for the regulation of axonal excitability discovered in our present study may play a critical role in synaptic modification in the developing hippocampus.

We showed that the fiber volley facilitation was induced by the neurotransmitter released by synaptic activity, using the general $\mathrm{Ca}^{2+}$ channel blocker $\mathrm{Cd}^{2+}$ (Fig. $4 A$ ). We also observed that $\mathrm{Cd}^{2+}$ abolished EPSPs (supplemental Fig. $1 B$, available at www.jneurosci.org as supplemental material), but had no effect on the fiber volley amplitude (supplemental Fig. $1 A$, available at www.jneurosci.org as supplemental material), indicating that the $\mathrm{Ca}^{2+}$ current at the presynaptic terminal was not a component of fiber volleys and that the fiber volley facilitation was not mediated by the modulation of $\mathrm{Ca}^{2+}$ influx into the presynaptic terminal. Furthermore, $\mathrm{Cd}^{2+}$ exhibited no effect on the muscimolinduced increase of fiber volley amplitudes (supplemental Fig. $1 A, C$, available at www.jneurosci.org as supplemental material). Therefore, we concluded that the fiber volley facilitation was induced by synaptically released GABA.

\section{The source of GABA responsible for the activity-dependent} facilitation of fiber volleys

Possible sources of GABA acting on presynaptic $\mathrm{GABA}_{\mathrm{A}}$ receptors are twofold: GABAergic interneurons and mossy fibers themselves. One possibility is that GABAergic interneurons were stimulated by mossy fibers via a feedforward disynaptic connec-
A

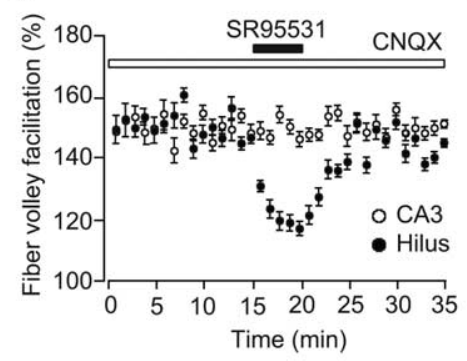

C

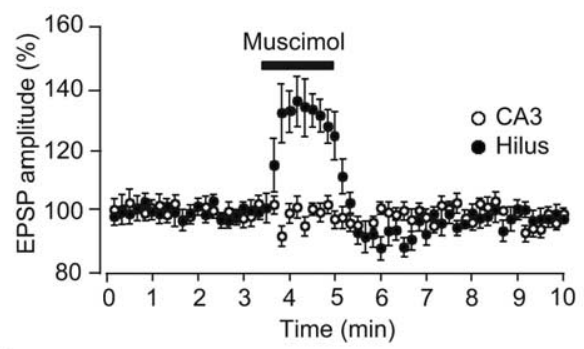

E

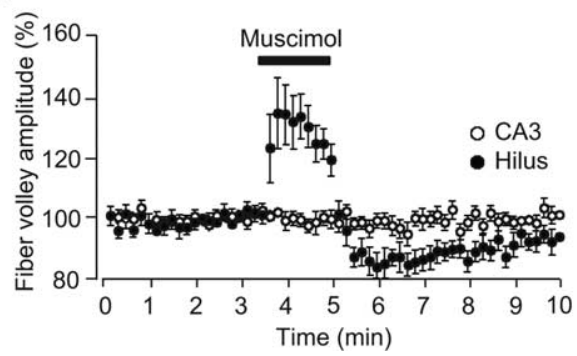

F

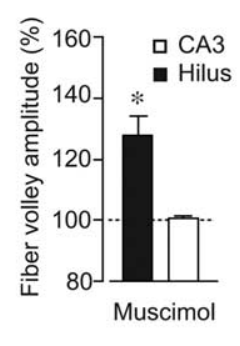

Figure 6. Identification of the site on which GABA acts for inducing the fiber volley facilitation. $\boldsymbol{A}$, The time course of the fiber volley facilitation (fifth/first) before, during, and after the local application of SR95531 (1 $\mu \mathrm{M})$ at the site close to the recording electrode (open circles, CA3) and close to the stimulating electrode (closed circles, Hilus). $\boldsymbol{B}$, Summary of the fiber volley facilitation in the presence of CNQX and CNQX + SR95531 and after the washout of SR95531 at the site close to the recording electrode (open columns, CA3) and close to the stimulating electrode (closed columns, Hilus). The facilitation was significantly suppressed by SR95531 locally applied near the stimulation site in the hilus. $\boldsymbol{C}$, The time course of the EPSP amplitude before, during, and after the local application of muscimol $(0.5 \mu \mathrm{m})$ at the site close to the recording electrode (open circles, $C A 3$ ) and close to the stimulating electrode (closed circles, Hilus). D, Enhancement of the EPSP amplitude by the local application of muscimol at the site close to the recording electrode (open column, CA3) and close to the stimulating electrode (closed columns, Hilus). $\boldsymbol{E}$, The time course of the fiber volley amplitude before, during, and after the local application of muscimol $(0.5 \mu \mathrm{m})$ at the site close to the recording electrode (open circles, (A3) and close to the stimulating electrode (closed circles, Hilus). $\boldsymbol{F}$, Enhancement of the fiber volley amplitude by the local application of muscimol at the site close to the recording electrode (open column, (A3) and close to the stimulating electrode (closed column, Hilus). ${ }^{*} p$ $<0.05$ (paired $t$ test).

tion. In fact, mossy fiber axons make synaptic contacts with several types of interneurons in the hilus and the CA3 region (Acsády et al., 1998; Lei and McBain, 2002). However, this possibility is very unlikely, because DCG-IV, which should block mossy fiber synaptic transmission, had no effect on the facilitation of fiber volleys (Fig. $4 B$ ) and because significant facilitation was still observed in the presence of CNQX (Fig. 4D, 8B), which should abolish synaptic transmission at the mossy fiber-interneuron synapse and prevent the disynaptic activation of $\mathrm{GABA}_{\mathrm{A}}$ receptors. Another possibility is that GABAergic interneurons were directly stimulated because we stimulated mossy fibers in the hilus, and this resulted in the release of GABA, which then activated axonal $\mathrm{GABA}_{\mathrm{A}}$ receptors synaptically or by spill-over.

Alternatively, the mossy fiber itself is also a candidate for the 


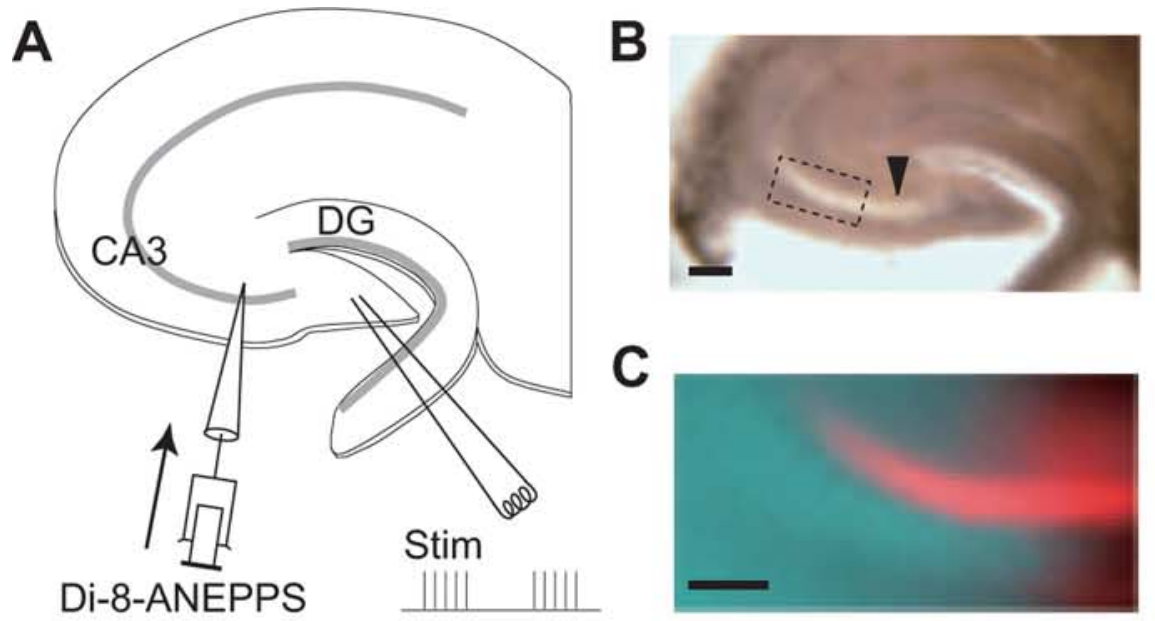

D

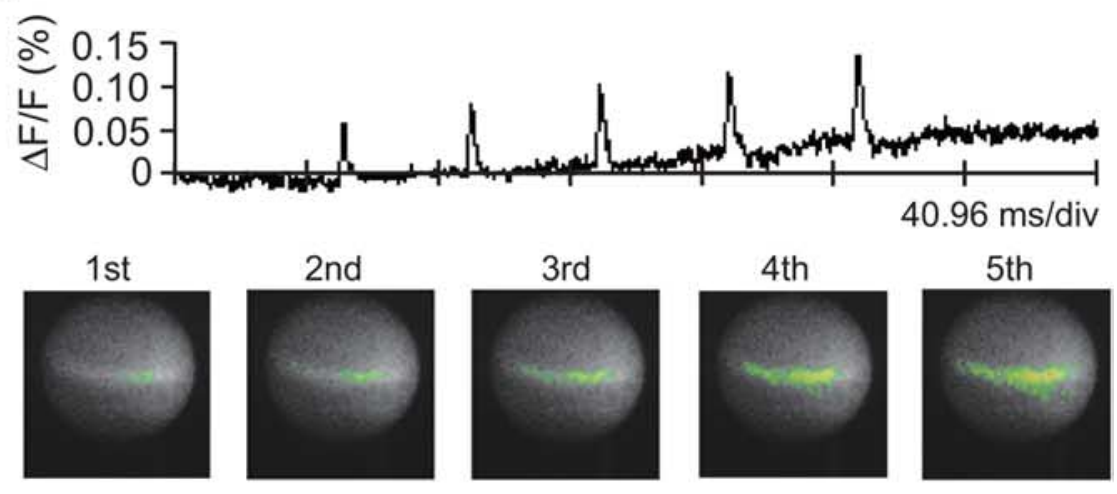

$E$

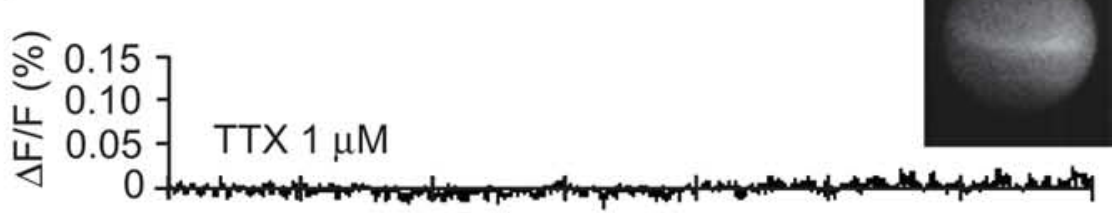

$40.96 \mathrm{~ms} / \mathrm{div}$

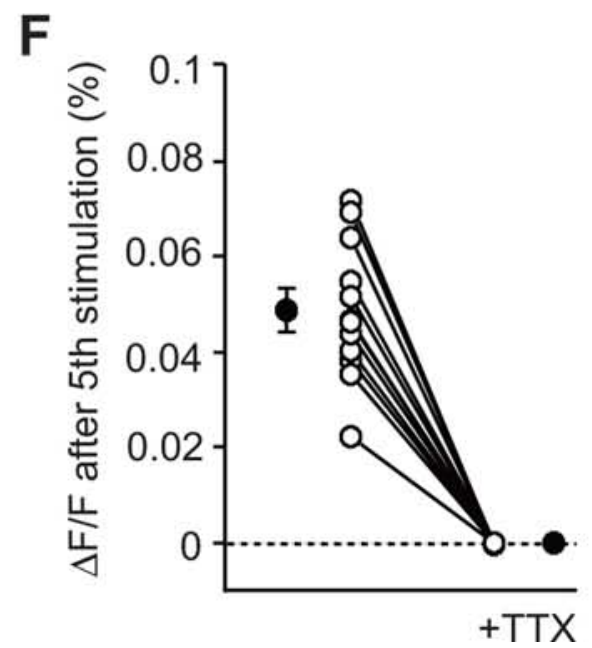

G

Figure 7. Optical imaging of the axonal voltage transient $(\Delta F / F)$ at the immature mossy fiber synapse. $A$, A schematic illustration of the experimental procedure. The voltage-sensitive dye Di-8-ANEPPS was locally pressure-injected into the stratum lucidum in the $\mathrm{CA} 3$ region along the mossy fiber bundle. The slice preparation and stimulation protocol were the same as those in source of GABA. Previous studies have suggested that DG granule cells express GABAergic phenotypes (Walker et al., 2001; Gutiérrez, 2003; Safiulina et al., 2006), which are gradually decreased with development, and eventually disappear at around P24, and the time course of the change in GABAergic phenotypes is similar to that of the fiber volley facilitation discovered in the present study (Figs. 3, $4 F$ ). However, it is unlikely that GABA released from the mossy fiber terminal activates presynaptic $\mathrm{GABA}_{\mathrm{A}}$ receptors, because DCG-IV had no effect on the fiber volley facilitation (Fig. $4 \mathrm{~B}$ ), and because L-(+)-2-amino-4-phosphonobutylic acid (L-AP4), which has been reported to inhibit GABA release from the mossy fiber terminal (Gutiérrez, 2003), also had no effect on the facilitation in our study (data not shown).

Thus, it is very likely that the fiber volley facilitation is induced by GABA released from interneurons activated by direct stimulation by the stimulating electrode. In fact, this scenario was supported by our observation (Fig. 8) that enkephalin, which selectively inhibits the excitability of GABAergic interneurons (Madison and Nicoll, 1988; Manzoni et al., 1994), significantly reduced the fiber volley facilitation. In this study, GABA was released by direct stimulation of interneurons; however, it has been well established that interneurons in the CA3 region are frequently activated by mossy fibers and heavily innervate the targets in the stratum lucidum, suggesting that a situation similar to the condition in our present study is likely to arise in the hippocampus under more physiological conditions.

\section{Physiological implications}

In the immature brain, $\mathrm{GABA}_{\mathrm{A}}$ receptor activation generally causes depolarization

\footnotetext{
electrophysiological experiments. $\boldsymbol{B}$, A light micrograph of a hippocampal slice. The arrowhead indicates the locus of the dye injection. Scale bar, $200 \mu \mathrm{m}$. C, A fluorescent image of the area indicated by the box in $\boldsymbol{B}$. Scale bar, $100 \mu \mathrm{m}$. $\boldsymbol{D}, \mathbf{A}$ trace representing the time course of $\Delta F / F$. Pseudocolor illustrations showing an increase in depolarization at the peak of each voltage transient. $\boldsymbol{E}$, A trace representing the time course of $\Delta \mathrm{F} / \mathrm{F}$ in the presence of $1 \mu \mathrm{m}$ TTX. A pseudocolor illustration showing no change in fluorescence on the fifth pulse. $\boldsymbol{F}$, The average of $\Delta \mathrm{F} / \mathrm{F}$ from 30 to $70 \mathrm{~ms}$ after the fifth pulse in the absence and presence of TTX. Open circles represent individual results, and the data points from the same slice are connected by the line. Closed circles indicate the means $(n=$ 12; $p<0.0001)$. $\mathbf{G}$, The facilitation of the fluorescence change $(\Delta F / F)$. Open circles represent the individual results, and a closed circle indicates the mean $(n=12 ; p=$ 0.000104).
} 


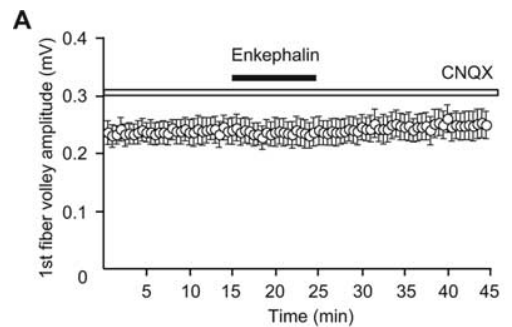

B

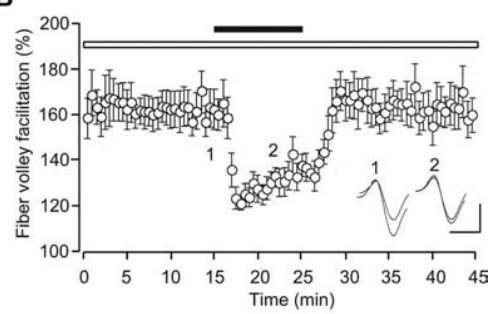

C

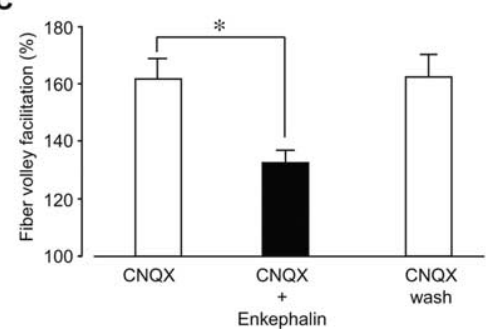

Figure 8. Effects of enkephalin on the fiber volley facilitation at immature mossy fiber synapses. $\boldsymbol{A}$, The time course of the first fiber volley amplitude before, during, and after the application of $1 \mu \mathrm{m}$ enkephalin in the presence of $10 \mu \mathrm{m}$ CNQX. $B$, The time course of the fiber volley facilitation (fifth/first) before, during, and after the application of $1 \mu \mathrm{m}$ enkephalin. In the inset, representative traces recorded at the times indicated by the numbers in the graph are shown. Calibration: $1 \mathrm{~ms}, 0.2 \mathrm{mV}$. C, Summary of the fiber volley facilitation (fifth/first) in the presence of CNQX (left open column) and CNQX + enkephalin (closed column) and after the washout of enkephalin (right open column). The facilitation was significantly suppressed by $1 \mu$ m enkepha$\operatorname{lin}(n=12) .{ }^{*} p<0.05$ (paired $t$ test).

rather than hyperpolarization in the postsynaptic neuron and, because glutamatergic synaptic transmission is not fully developed, GABA released from interneurons plays a major role as an excitatory neurotransmitter (Ben-Ari, 2002). In the present study, we have extended this notion to the axonal $\mathrm{GABA}_{\mathrm{A}}$ receptor in the mossy fiber. One way to supplement relatively weak excitation by glutamatergic inputs in the immature brain is direct postsynaptic depolarization caused by depolarizing GABAergic inputs, whereas another way is increasing the efficacy of glutamatergic inputs through presynaptic facilitation. Although the mossy fiber synapse exhibits large frequency facilitation even at early developmental stages, axonal depolarization by GABAergic inputs should further increase the glutamatergic synaptic efficacy around twofold in an activity-dependent manner. When the increased synaptic efficacy and fiber volley facilitation take place at the same time, the latter should considerably contribute to the facilitation in total. Thus, this mechanism may selectively increase the information flow from the DG to the CA3 region only at early developmental stages. Because long-term synaptic plasticity at mossy fiber synapses is also dynamically regulated by presynaptic mechanisms (Manabe, 1997; Nicoll and Schmitz, 2005), this novel presynaptic regulation may be required for the process of memory formation in which mossy fiber synapses are involved.

The two characteristic features of the fiber volley facilitation discovered in our present study are as follows: (1) the fiber volley in response to the first pulse of the train was never affected by GABAergic antagonists (Fig. 4C), and (2) the fiber volley in response to the second pulse delivered $40 \mathrm{~ms}$ after the first pulse clearly showed the facilitation at P10 (Fig. 2C), but not at P30 (Fig. $1 E$ ). Ruiz et al. (2003) reported that $\mathrm{GABA}_{\mathrm{A}}$ receptor activation reduced mossy fiber excitability and that $\mathrm{GABA}_{\mathrm{A}}$ receptors modulating the axonal excitability were tonically activated by ambient GABA. However, in our present study, $\mathrm{GABA}_{\mathrm{A}}$ receptor activation increased the excitability of mossy fibers, and the amplitude of the first fiber volley was never reduced by $\mathrm{GABA}_{\mathrm{A}}$ receptor antagonists. Ruiz et al. (2003) examined the effect of the $\mathrm{GABA}_{\mathrm{A}}$ receptor agonist muscimol applied by pressure ejection at the stimulation site in the stratum lucidum, whereas we observed the positive effect of the $\mathrm{GABA}_{\mathrm{A}}$ receptor antagonist SR95531 and muscimol in the hilus, but no effect in the stratum lucidum (Fig. 6). Therefore, the discrepancy in the tonic activation of presynaptic $\mathrm{GABA}_{\mathrm{A}}$ receptors between the two studies may stem from the difference in the subunit composition in different hippocampal regions. Another important factor that may account for the discrepancy is the age of animals. Whereas we used mice aged 10 d, Ruiz et al. (2003) used young adult guinea pigs (3-4 weeks old). Thus, the phenomenon observed in their study may be mediated by a different subset of $\mathrm{GABA}_{\mathrm{A}}$ receptors from that in our present study, or the phenomena themselves may be mechanistically different. Alternatively, the discrepancy in the effect of GABA on mossy fiber excitability may be accounted for by the difference in intracellular $\mathrm{Cl}^{-}$concentrations in axons, which determine the reversal potential of $\mathrm{GABA}_{\mathrm{A}}$ receptor channels. It is generally believed that the intracellular $\mathrm{Cl}^{-}$ concentration is higher in younger animals (Ben-Ari, 2002), which may explain why Ruiz et al. (2003) observed the reduction of mossy fiber excitability, but we observed the increase of excitability. In the spinal cord, similar depolarization mediated by $\mathrm{GABA}_{\mathrm{A}}$ receptors at the synaptic terminal was reported (Nicoll and Alger, 1979) and the depolarization was associated with presynaptic inhibition, but not facilitation, which is consistent with Ruiz et al. (2003). Therefore, it is possible that depolarization at the terminal may result in synaptic inhibition, whereas depolarization at the axon may result in synaptic facilitation as observed in the present study. Another possibility is that the property of presynaptic $\mathrm{GABA}_{\mathrm{A}}$ receptors may be different between species [guinea pigs in the study of Ruiz et al. (2003) and mice in our study].

In the present study, the second fiber volley during the train stimulation was clearly enhanced at P10, but unaltered at P30. The larger paired-pulse facilitation at immature mossy fiber synapses reported by Mori-Kawakami et al. (2003) might reflect this activity- and age-dependent fiber volley facilitation. The effect of bath-applied muscimol on fiber volleys was also changed in an age-dependent manner (Fig. 5C); however, the change was less pronounced than that of the synaptically induced fiber volley facilitation (Fig. 3). This difference might indicate that the GABA release, rather than the number of axonal $\mathrm{GABA}_{\mathrm{A}}$ receptors, is more preferentially downregulated during development. Alternatively, the difference between physiological release of GABA and bath-application of GABA might produce an apparent difference in the developmental profile of these phenomena.

In this study, we have elucidated the novel role of axonal $\mathrm{GABA}_{\mathrm{A}}$ receptors. Important next steps would be to determine how the expression of $\mathrm{GABA}_{\mathrm{A}}$ receptors on mossy fiber axons is developmentally regulated and how the activation of the receptors modulates neural activity in the hippocampus as a whole. It is also critical to elucidate the role of the $\mathrm{GABA}_{\mathrm{A}}$ receptor-mediated 
fiber volley facilitation in activity-dependent synaptic maturation of the mossy fiber-CA3 synapse.

\section{References}

Acsády L, Kamondi A, Sik A, Freund T, Buzsaki G (1998) GABAergic cells are the major postsynaptic targets of mossy fibers in the rat hippocampus. J Neurosci 18:3386-3403.

Amaral DG, Dent JA (1981) Development of the mossy fibers of the dentate gyrus: I. A light and electron microscopic study of the mossy fibers and their expansions. J Comp Neurol 195:51-86.

Ben-Ari Y (2002) Excitatory actions of GABA during development: the nature of the nurture. Nat Rev Neurosci 3:728-739.

Blatow M, Caputi A, Burnashev N, Monyer H, Rozov A (2003) $\mathrm{Ca}^{2+}$ buffer saturation underlies paired pulse facilitation in calbindin-D28kcontaining terminals. Neuron 38:79-88.

Geiger JR, Jonas P (2000) Dynamic control of presynaptic $\mathrm{Ca}^{2+}$ inflow by fast-inactivating $\mathrm{K}^{+}$channels in hippocampal mossy fiber boutons. Neuron 28:927-939.

Gutiérrez R (2003) The GABAergic phenotype of the "glutamatergic" granule cells of the dentate gyrus. Prog Neurobiol 71:337-358.

Henze DA, Urban NN, Barrionuevo G (2000) The multifarious hippocampal mossy fiber pathway: a review. Neuroscience 98:407-427.

Henze DA, Wittner L, Buzsaki G (2002) Single granule cells reliably discharge targets in the hippocampal CA3 network in vivo. Nat Neurosci 5:790-795.

Jang IS, Nakamura M, Ito Y, Akaike N (2006) Presynaptic GABA receptors facilitate spontaneous glutamate release from presynaptic terminals on mechanically dissociated rat CA3 pyramidal neurons. Neuroscience 138:25-35.

Kamiya H, Ozawa S (2000) Kainate receptor-mediated presynaptic inhibition at the mouse hippocampal mossy fibre synapse. J Physiol (Lond) 523:653-665.

Kamiya H, Shinozaki H, Yamamoto C (1996) Activation of metabotropic glutamate receptor type $2 / 3$ suppresses transmission at rat hippocampal mossy fiber synapses. J Physiol (Lond) 493:447-455.

Kamiya H, Ozawa S, Manabe T (2002) Kainate receptor-dependent shortterm plasticity of presynaptic $\mathrm{Ca}^{2+}$ influx at the hippocampal mossy fiber synapses. J Neurosci 22:9237-9243.

Katz B, Miledi R (1968) The role of calcium in neuromuscular facilitation. J Physiol (Lond) 195:481-492.

Kobayashi K, Manabe T, Takahashi T (1996) Presynapticlong-term depression at the hippocampal mossy fiber-CA3 synapse. Science 273:648-650.

Lei S, McBain CJ (2002) Distinct NMDA receptors provide differential modes of transmission at mossy fiber-interneuron synapses. Neuron 33:921-933.

Lynch MA (2004) Long-term potentiation and memory. Physiol Rev 84:87-136.

Madison DV, Nicoll RA (1988) Enkephalin hyperpolarized interneurones in the rat hippocampus. J Physiol (Lond) 398:123-130.

Manabe T (1997) Two forms of hippocampal long-term depression, the counterpart of long-term potentiation. Rev Neurosci 8:179-193.

Manzoni OJ, Manabe T, Nicoll RA (1994) Release of adenosine by activation of NMDA receptors in the hippocampus. Science 265:2098-2101.

Milner B, Squire LR, Kandel ER (1998) Cognitive neuroscience and the study of memory. Neuron 20:445-468.

Mori-Kawakami F, Kobayashi K, Takahashi T (2003) Developmental decrease in synaptic facilitation at the mouse hippocampal mossy fibre synapse. J Physiol (Lond) 553:37-48.

Nicoll RA, Alger BE (1979) Presynaptic inhibition: transmitter and ionic mechanisms. Int Rev Neurobiol 21:217-258.

Nicoll RA, Schmitz D (2005) Synaptic plasticity at hippocampal mossy fibre synapses. Nat Rev Neurosci 6:863-876.

Ruiz A, Fabian-Fine R, Scott R, Walker MC, Rusakov DA, Kullmann DM (2003) $\mathrm{GABA}_{\mathrm{A}}$ receptors at hippocampal mossy fibers. Neuron 39:961-973.

Safiulina VF, Fattorini G, Conti F, Cherubini E (2006) GABAergic signaling at mossy fiber synapses in neonatal rat hippocampus. J Neurosci 26:597-608.

Schmitz D, Mellor J, Nicoll RA (2001) Presynaptic kainate receptor mediation of frequency facilitation at hippocampal mossy fiber synapses. Science 291:1972-1976.

Stumm RK, Zhou C, Schulz S, Hollt V (2004) Neuronal types expressing $\mu$ and $\delta$-opioid receptor mRNA in the rat hippocampal formation. J Comp Neurol 469:107-118.

Vogt KE, Nicoll RA (1999) Glutamate and $\gamma$-aminobutyric acid mediate a heterosynaptic depression at mossy fiber synapses in the hippocampus. Proc Natl Acad Sci USA 96:1118-1122.

Walker MC, Ruiz A, Kullmann DM (2001) Monosynaptic GABAergic signaling from dentate to CA3 with a pharmacological and physiological profile typical of mossy fiber synapses. Neuron 29:703-715.

Yokoi M, Kobayashi K, Manabe T, Takahashi T, Sakaguchi I, Katsuura G, Shigemoto R, Ohishi H, Nomura S, Nakamura K, Nakao K, Katsuki M, Nakanishi S (1996) Impairment of hippocampal mossy fiber LTD in mice lacking mGluR2. Science 273:645-647.

Zucker RS, Regehr WG (2002) Short-term synaptic plasticity. Annu Rev Physiol 64:355-405. 